\title{
One-pot synthesis of Au nanoparticles/reduced graphene oxide nanocomposites and their application for electrochemical $\mathrm{H}_{2} \mathrm{O}_{2}$, glucose, and hydrazine sensing
}

\author{
Xiaoyun Qin • Qingzhen Li • Abdullah M. Asiri • \\ Abdulrahman O. Al-Youbi $\cdot$ Xuping Sun
}

Published online: 9 August 2013

(C) The Author(s) 2013. This article is published with open access at SpringerLink.com

\begin{abstract}
In this paper, Au nanoparticles/reduced graphene oxide (AuNPs/rGO) nanocomposites were prepared through a one-pot strategy, carried out by heating the mixture of $\mathrm{HAuCl}_{4}$ and graphene oxide solution at $90{ }^{\circ} \mathrm{C}$ under alkaline condition. The resultant AuNPs/rGO nanocomposites were found to exhibit good catalytic performance toward $\mathrm{H}_{2} \mathrm{O}_{2}$ reduction and oxidation as well as hydrazine oxidation. The electrochemical sensing application of the nanocomposites for $\mathrm{H}_{2} \mathrm{O}_{2}$, glucose, and hydrazine was also demonstrated successfully.
\end{abstract}

Keywords Au nanoparticles $\cdot$ Reduced graphene oxide Electrochemical detection $\cdot \mathrm{H}_{2} \mathrm{O}_{2} \cdot$ Glucose $\cdot$ Hydrazine

\section{Introduction}

Graphene, a two-dimensional aromatic sheets composed of $\mathrm{sp}^{2}$ bonded carbon atoms, has received enormous interest in various areas of research owing to its large specific surface area, excellent thermal and electrical conductivity, strong mechanical strength, good biocompatibility, and low manufacturing cost [1-3]. On the

X. Qin· Q. Li · X. Sun

Chemical Synthesis and Pollution Control Key Laboratory of Sichuan Province, School of Chemistry and Chemical Industry, China West Normal University, Nanchong 637002 Sichuan, China

A. M. Asiri · A. O. Al-Youbi · X. Sun

Chemistry Department, Faculty of Science, King Abdulaziz

University, Jeddah 21589, Saudi Arabia

A. M. Asiri • A. O. Al-Youbi $\cdot$ X. Sun $(\bowtie)$

Center of Excellence for Advanced Materials Research, King

Abdulaziz University, Jeddah 21589, Saudi Arabia

e-mail: sun.xuping@hotmail.com other hand, noble metal nanostructures are a class of functional materials with unique physical and chemical properties [4, 5]. Furthermore, the integration of two-dimensional graphene with zero-dimensional noble metal nanoparticles (NPs) into hybrid structures has received increased attention in the past few years [6-12]. These noble metal NPs/graphene nanocomposites not only combine the merits of each component, but possess interesting structural, electrochemical, electromagnetic, and other properties that are not available in their respective components. We have fabricated noble metal NPs/graphene nanocomposites via chemical reduction and photocatalytic strategies [13-23]. Zhou et al. demonstrated the one-step synthesis of AgNPs on graphene oxide $(\mathrm{GO})$ and reduced graphene oxide $(\mathrm{rGO})$ surfaces absorbed on 3-aminopropyltriethoxysilane-modified $\mathrm{Si} / \mathrm{SiO}_{x}$ substrates without using any surfactant or reducing agent [24]. Similarly, our group has also successfully reduced GO to rGO in liquid phase and decorated AgNPs onto thus obtained rGO under strong alkaline conditions without any reducing agent $[25,26]$. In this process, AgNPs are deposited onto rGO by chemical reduction of silver ions by hydroxyl group of GO accompanied with the conversion of GO into rGO under strong alkaline conditions as well as heat treatment process [27-30]. However, high temperature or multistep reactions are required. Accordingly, from a point view of material science, synthesis of noble metal NPs/graphene nanocomposites by a more facile method and exploiting their catalytic applications are still highly desirable. Herein, we prepared AuNPs/rGO nanocomposites through a one-pot route by heating the mixture of $\mathrm{HAuCl}_{4}$ and GO solution under alkaline condition at $90{ }^{\circ} \mathrm{C}$ for $30 \mathrm{~min}$. It suggests that the resultant AuNPs/rGO nanocomposites show good catalytic performance toward $\mathrm{H}_{2} \mathrm{O}_{2}$ reduction and oxidation as well as hydrazine oxidation. We further demonstrate the electrochemical sensing application of the nanocomposites for $\mathrm{H}_{2} \mathrm{O}_{2}$, glucose, and hydrazine. 


\section{Material and methods}

Reagents and materials

Graphite powder, $\mathrm{NaCl}, \mathrm{NaH}_{2} \mathrm{PO}_{4}, \mathrm{Na}_{2} \mathrm{HPO}_{4}, \mathrm{HAuCl}_{4}$, and $\mathrm{H}_{2} \mathrm{O}_{2}(30 \%)$ were from Aladin Ltd. (Shanghai, China). Glucose, $\mathrm{NaNO}_{3}, \mathrm{H}_{2} \mathrm{SO}_{4}\left(98 \%\right.$ ), and $\mathrm{KMnO}_{4}$ were purchased from Beijing Chemical Corp. glucose oxidase (GOD) was purchased from Aldrich Chemical Inc. All chemicals were used as received without further purification. The water used throughout all experiments was purified through a Millipore system and a fresh solution of $\mathrm{H}_{2} \mathrm{O}_{2}$ was prepared daily. Phosphate-buffered saline (PBS) was prepared by mixing stock solutions of $\mathrm{NaH}_{2} \mathrm{PO}_{4}, \mathrm{Na}_{2} \mathrm{HPO}_{4}$, and $\mathrm{NaCl}$.

Preparation of GO

GO was prepared from natural graphite powder through a modified Hummers method [31]. In a typical synthesis, $1 \mathrm{~g}$ of graphite was added into $23 \mathrm{~mL}$ of $98 \% \mathrm{H}_{2} \mathrm{SO}_{4}$, followed by stirring at room temperature over a $24-\mathrm{h}$ period. After that, $100 \mathrm{mg}$ of $\mathrm{NaNO}_{3}$ was introduced into the mixture and stirred for $30 \mathrm{~min}$. Subsequently, the mixture was kept below $5{ }^{\circ} \mathrm{C}$ by ice bath, and $3 \mathrm{~g}$ of $\mathrm{KMnO}_{4}$ was slowly added into the mixture. After being heated to $35-40{ }^{\circ} \mathrm{C}$, the mixture was stirred for another $30 \mathrm{~min}$. After that, $46 \mathrm{~mL}$ of water was added into above mixture during a period of $25 \mathrm{~min}$. Finally, $140 \mathrm{~mL}$ of water and $10 \mathrm{~mL}$ of $30 \%$ $\mathrm{H}_{2} \mathrm{O}_{2}$ were added into the mixture to stop the reaction. After the unexploited graphite in the resultant mixture was removed by centrifugation, as-synthesized GO was dispersed into individual sheets in distilled water at a concentration of $0.5 \mathrm{mg} / \mathrm{mL}$ with the aid of ultrasound for further use.

Preparation of AuNPs/rGO nanocomposites

In a typical experiment, $155 \mu \mathrm{L}$ of $\mathrm{HAuCl}_{4}$ aqueous solution $(24.3 \mathrm{mM})$ was mixed with the $4,650-\mu \mathrm{L} 0.25 \mathrm{mg} / \mathrm{mL}$ of $\mathrm{GO}$ and $195 \mu \mathrm{L} 8 \mathrm{M} \mathrm{NaOH}$. Then, the mixture was heated to $90{ }^{\circ} \mathrm{C}$ for $30 \mathrm{~min}$ in a hot bath. The products were collected by centrifugation and washed with water three times. Finally, the resulting precipitates were redispersed in water for characterization and further use.

\section{Electrochemical measurements}

The electrochemical measurements were performed with a CHI 660D electrochemical analyzer (CH Instruments, Inc., Shanghai). A conventional three-electrode cell was used, including a glassy carbon electrode (GCE) (geometric area= $\left.0.07 \mathrm{~cm}^{2}\right)$ as the working electrode, a $\mathrm{Ag} / \mathrm{AgCl}(3 \mathrm{M} \mathrm{KCl})$ electrode as the reference electrode, and platinum foil as the counter electrode. All potentials given in this work were referred to the $\mathrm{Ag} / \mathrm{AgCl}$ electrode. All the experiments were carried out at ambient temperature. The modified electrode was prepared via a simple casting method. Prior to the surface coating, the GCE was polished with 1.0 and $0.3 \mu \mathrm{m}$ alumina powder, respectively. After that, the GCE was rinsed with distilled water, followed by sonication in ethanol and distilled water, respectively. Then, the electrode was allowed to dry in a stream of nitrogen. For the determination of $\mathrm{H}_{2} \mathrm{O}_{2}, 3 \mu \mathrm{L}$ of AuNPs/rGO nanocomposites was dropped on the surface of pretreated GCE and left to dry at room temperature. Then, $4 \mu \mathrm{L}$ of $38 \mathrm{mg} / \mathrm{mL}$ GOD aqueous solution was dropped on the resulting AuNPs/rGO/GCE to dry at $4{ }^{\circ} \mathrm{C}$ for $3 \mathrm{~h}$. For current time experiment, $2 \mu \mathrm{L}$ of $1 \mathrm{wt} \%$ chitosan solution was used as a fixative and additionally casted on the surface of the above materials modified GCE and dried at $4{ }^{\circ} \mathrm{C}$ for $2 \mathrm{~h}$ before electrochemical experiments.

Instruments

UV-vis spectra were obtained on a UV5800 spectrophotometer. Raman spectra were obtained on J-Y T64000 Raman spectrometer with $514.5 \mathrm{~nm}$ wavelength incident laser light. Powder X-ray diffraction (XRD) data were recorded on a Rigaku D/MAX 2550 diffractometer with $\mathrm{Cu} \mathrm{K} \alpha$ radiation $(\lambda=1.5418 \AA)$. Transmission electron microscopy (TEM) measurements were made on a Hitachi $\mathrm{H}$ 8100 EM (Hitachi, Tokyo, Japan) with an accelerating applied potential of $200 \mathrm{kV}$. The sample for TEM characterization was prepared by placing a drop of the dispersion on carbon-coated copper grid and drying at room temperature.

\section{Results and discussion}

\section{Characterization of AuNPs/rGO nanocomposites}

Figure 1 shows the Raman spectra of aqueous dispersion of GO (curve a) and the products (curve b). It is seen that GO exhibits a D band at $1,361 \mathrm{~cm}^{-1}$ and a $\mathrm{G}$ band at $1,608 \mathrm{~cm}^{-1}$, while the corresponding bands of the products are 1,354 and $1,579 \mathrm{~cm}^{-1}$, respectively. The $\mathrm{G}$ band of the products redshifts from 1,608 to $1,579 \mathrm{~cm}^{-1}$, which is attributed to the high ability for recovery of the hexagonal network of carbon atom [32]. It is also found that the products show relative higher intensity of $\mathrm{D}$ to $\mathrm{G}$ band $(0.97)$ than that of GO (0.79), further confirming the formation of new graphitic domains [33]. These observations confirm the successful conversion of GO to rGO after the heat treatment process under alkali conditions.

Figure 2 shows the UV-vis spectra of aqueous dispersion of GO and resulting products. As expected, GO exhibits strong bands centered at 230 and $290 \mathrm{~nm}$, corresponding to 


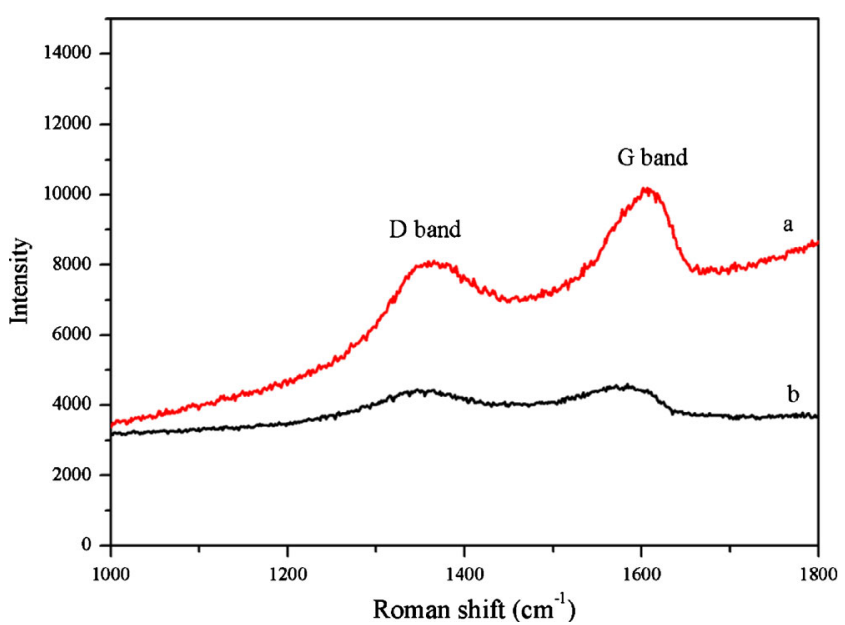

Fig. 1 Raman spectra of (curve a) GO and (curve b) the products obtained

$\pi-\pi^{*}$ transitions of aromatic $\mathrm{C}=\mathrm{C}$ band and $n-\pi^{*}$ transitions of $\mathrm{C}=\mathrm{O}$ band in $\mathrm{GO}$, respectively (curve a) [34]. It is clearly seen that the adsorption peak of the obtained composites gradually red-shifts from 230 to $260 \mathrm{~nm}$, and the absorbance in the whole spectral region increases after heat treatment (curve b), suggesting the successful reduction of GO [13, 35]. It is worthwhile mentioning the obvious color change from pale yellow to black after heat treatment of the mixture in alkaline conditions, revealing another piece of evidence to support the formation of rGO. Additionally, a new absorption band appears at $528 \mathrm{~nm}$ ascribing to the characteristic of the colloidal Au surface plasmon resonance band, indicating the formation of AuNPs [36].

The XRD pattern of the products obtained is shown in Fig. 3. The four peaks located at $38.2,44.5,64.8$, and $77.6^{\circ}$ are assigned to $111,200,220$, and 311 faces of a Au crystal, respectively, demonstrating the formation of metallic $\mathrm{Au}$

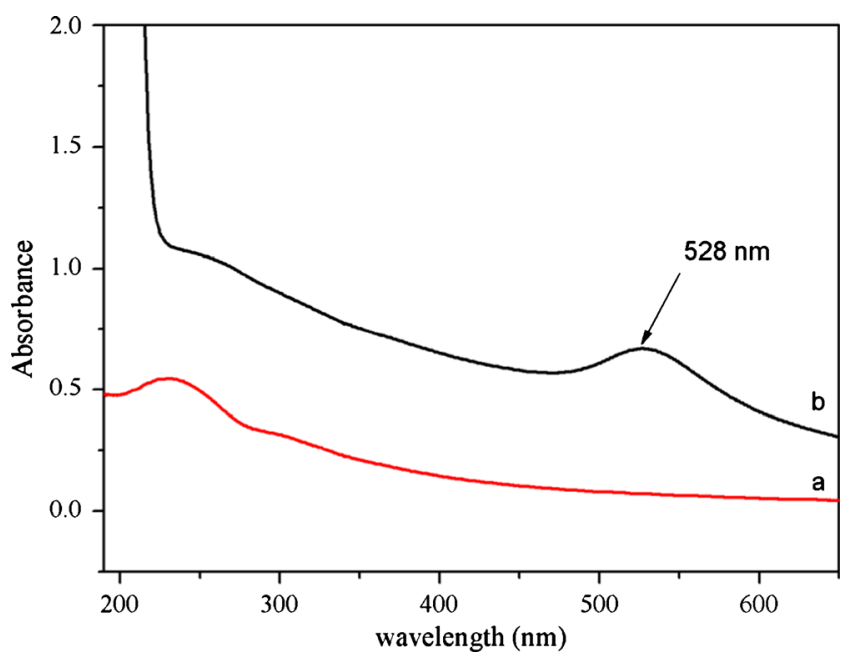

Fig. 2 UV-vis absorption spectra of aqueous dispersions of (curve a) $\mathrm{GO}$ and (curve $b$ ) the products obtained

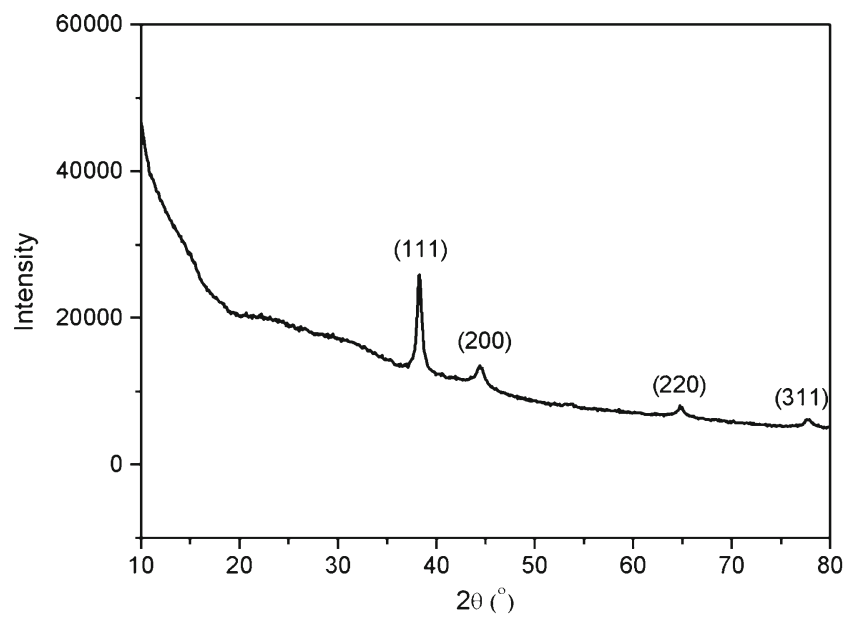

Fig. 3 XRD pattern of products obtained

(JCPDS 04-0784). The broad peak at $2 \theta=20-30^{\circ}$ appears, indicating the disordered stacking of $\mathrm{rGO}$ sheets in the composites [37]. All of these observations confirm the formation of AuNPs/rGO nanocomposites after the heat treatment of the mixture of $\mathrm{HAuCl}_{4}$ and $\mathrm{GO}$ solution under alkali conditions.

The formation of AuNPs/rGO nanocomposites was further confirmed by TEM observations. Figure 4 shows typical TEM images and the corresponding energy-dispersed spectrum (EDS). Low magnification image (Fig. 4a) indicates that numerous nanoparticles are attached onto the surface of rGO. A higher magnification image reveals the AuNPs are about $40 \mathrm{~nm}$ in diameter and the shape is mostly spherical (Fig. 4b). The chemical composition of the nanocomposites was determined by EDS (Fig. 4c), further confirming the existence of $\mathrm{C}, \mathrm{O}$, and $\mathrm{Au}$ elements. Other peaks originate from the ITO-coated glass substrate.

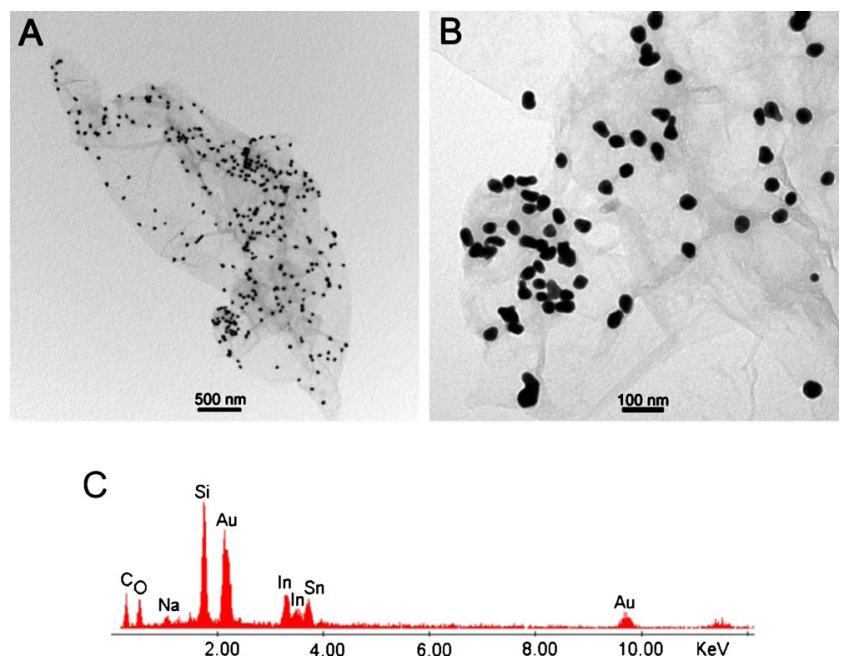

Fig. 4 Typical TEM images at (a) low and (b) high magnifications and (c) corresponding EDS of the obtained AuNPs/rGO nanocomposites 
The reducing nature of GO under alkaline conditions has been discussed by Kannan and Zhou et al. The hydroxyl groups of the molecules attached to the hexagonal basal plane make $\mathrm{GO}$ a proper agent to reduce $\mathrm{AuCl}_{4}{ }^{-}$under alkaline conditions [27]. Because the electrons in the negatively charged $\mathrm{rGO}$ can participate in the reduction of metal complex, $\mathrm{AuCl}_{4}{ }^{-}$could obtain the electrons in the negatively charged rGO surface to form AuNPs. The big difference between the reduction potential of $\mathrm{rGO}$ and $\mathrm{AuCl}_{4}{ }^{-}$also help to the spontaneous reduction process [24]. Meanwhile, the alkaline conditions can also accelerate the formation of rGO and AuNPs [28-30]. The strong alkali, $\mathrm{NaOH}$, plays a dual role in the conversion of GO and the formation of AuNPs in this system. In this way, AuNPs are deposited onto $\mathrm{rGO}$ by chemical reduction of $\mathrm{AuCl}_{4}{ }^{-}$by hydroxyl group of GO accompanied with the conversion of GO into rGO under strong alkaline conditions as well as heat treatment process.

\section{Electrocatalytic effect toward $\mathrm{H}_{2} \mathrm{O}_{2}$ of AuNPs/rGO/GCE}

To demonstrate the sensing application of AuNPs/rGO nanocomposites, we first constructed an enzymeless $\mathrm{H}_{2} \mathrm{O}_{2}$ sensor by immobilizing AuNPs/rGO nanocomposites with chitosan as a fixative onto a GCE surface. Figure 5a shows cyclic voltammograms (CVs) of bare GCE and the AuNPs/rGO/GCE in $0.2 \mathrm{M}$ PBS at $\mathrm{pH} 7.4$ in the presence of $1 \mathrm{mM} \mathrm{H}_{2} \mathrm{O}_{2}$. It is seen that the response of the bare GCE toward $\mathrm{H}_{2} \mathrm{O}_{2}$ is quite weak. In contrast, the AuNPs/rGO/GCE exhibits notable catalytic current in the process of both reduction and oxidation of $\mathrm{H}_{2} \mathrm{O}_{2}$. It is also important to note that the AuNPs/rGO/GCE exhibits no electrochemical response in the absence of $\mathrm{H}_{2} \mathrm{O}_{2}$. All these observations indicate that such AuNPs/rGO nanocomposites exhibit notable electrocatalytic activity toward both the reduction and oxidation of $\mathrm{H}_{2} \mathrm{O}_{2}$. The typical current-time curve of the AuNPs/rGO/GCE was shown in Fig. 5b. The amperometric response of the sensor was studied by successively dropping the $\mathrm{H}_{2} \mathrm{O}_{2}$ solution with different concentrations into the PBS under optimized conditions at an applied potential of $-0.3 \mathrm{~V}$ vs. $\mathrm{Ag} / \mathrm{AgCl}$ electrode. The linear range of the $\mathrm{H}_{2} \mathrm{O}_{2}$ detection was from 0.1 to $9 \mathrm{mM}$ $(r=0.999)$, and the detection limit was estimated to be $1.5 \mu \mathrm{M}$ based on the criterion of a signal-to-noise ratio of 3 .

\section{Determination of glucose at GOD/AuNPs/rGO/GCE}

Based on the high electrocatalytical activity of AuNPs/rGO/GCE toward $\mathrm{H}_{2} \mathrm{O}_{2}$, a glucose sensor was further developed by immobilizing GOD onto the surface of AuNPs/rGO/GCE. The sensing mechanism is that GOD can selectively catalyze the oxidation of glucose in the presence of oxygen to form $\mathrm{H}_{2} \mathrm{O}_{2}$, which can be electrochemically detected [38]. Differential pulse voltammogram (DPV) has
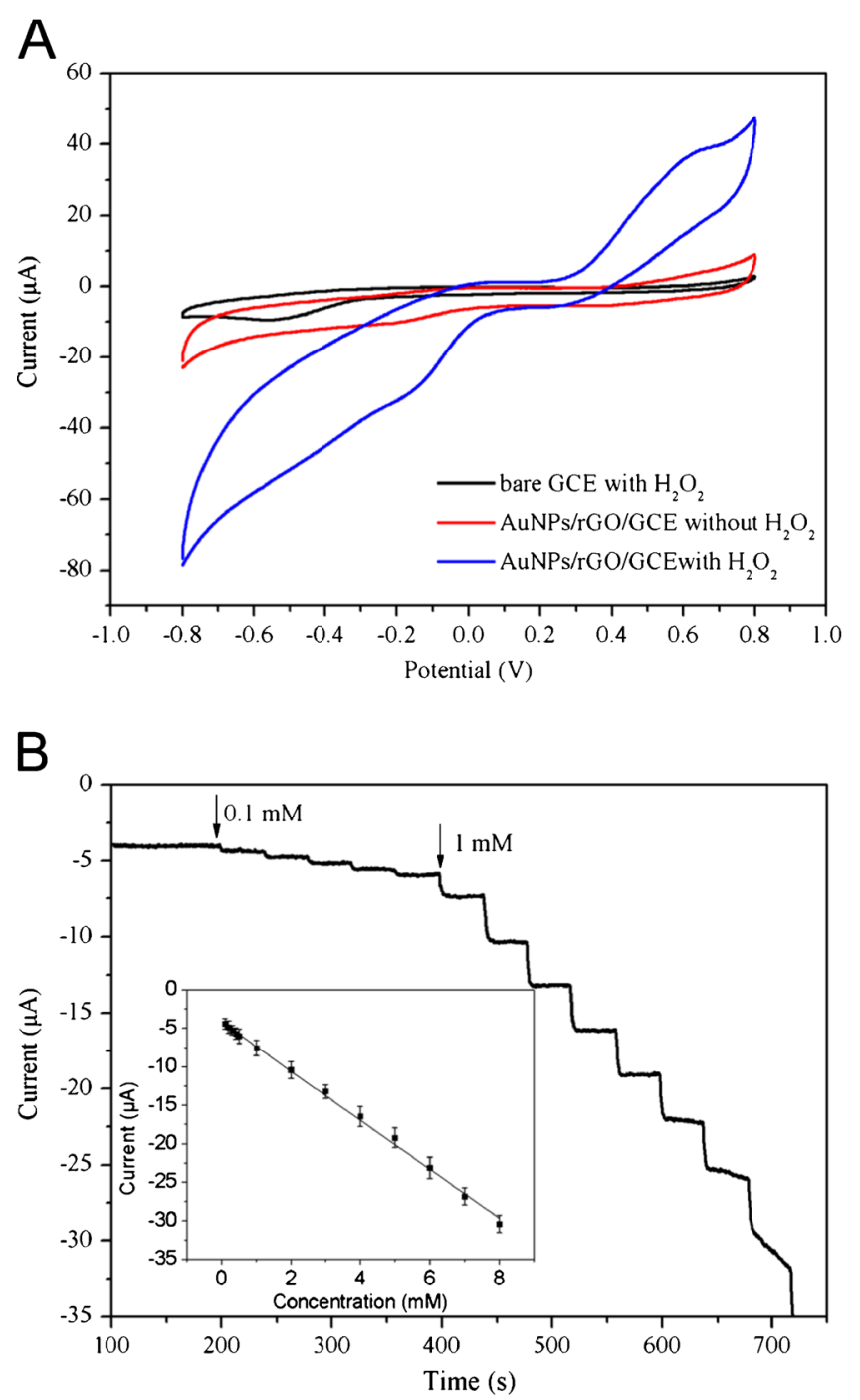

Fig. 5 a CVs of different electrodes in $\mathrm{N}_{2}$-saturated 0.2 M PBS at $\mathrm{pH}$ 7.4 in the presence and absence of $1 \mathrm{mM} \mathrm{H}_{2} \mathrm{O}_{2}$ (scan rate, $50 \mathrm{mV} \mathrm{s}^{-1}$ ). b Typical steady-state response of the AuNPs/rGO/GCE to successive injection of $\mathrm{H}_{2} \mathrm{O}_{2}$ into the stirred $\mathrm{N}_{2}$-saturated $0.2 \mathrm{M}$ PBS at $\mathrm{pH} 7.4$ (applied potential, $-0.3 \mathrm{~V}$ ). Inset: the fitting of the experimental data by the regression line

higher sensitivity than $\mathrm{CV}$ and is used for quantitative measurements in the current study. Figure 6 shows the typical DPVs of the GOD/AuNPs/rGO/GCE in $0.2 \mathrm{M}$ PBS solution at $\mathrm{pH} 7.4$ with various concentrations of glucose in saturated $\mathrm{O}_{2}$. It is seen that well-defined anodic peaks at $-0.07 \mathrm{~V}$ are observed, which can be attributed to the electrochemical oxidation of $\mathrm{H}_{2} \mathrm{O}_{2}$. It is also found that the oxidation current increases with the increased amount of glucose in saturated $\mathrm{O}_{2}$. The inset in Fig. 6 shows the calibration curves to corresponding amperometric responses. Good linear relationships are observed between the catalytic current and glucose concentration at ranges from 0 to $1 \mathrm{mM}(r=0.998)$ and from 3 to $21 \mathrm{mM}(r=0.996)$, respectively. The detection limit is estimated to be $20 \mu \mathrm{M}$ with a signal-to-noise ratio of 


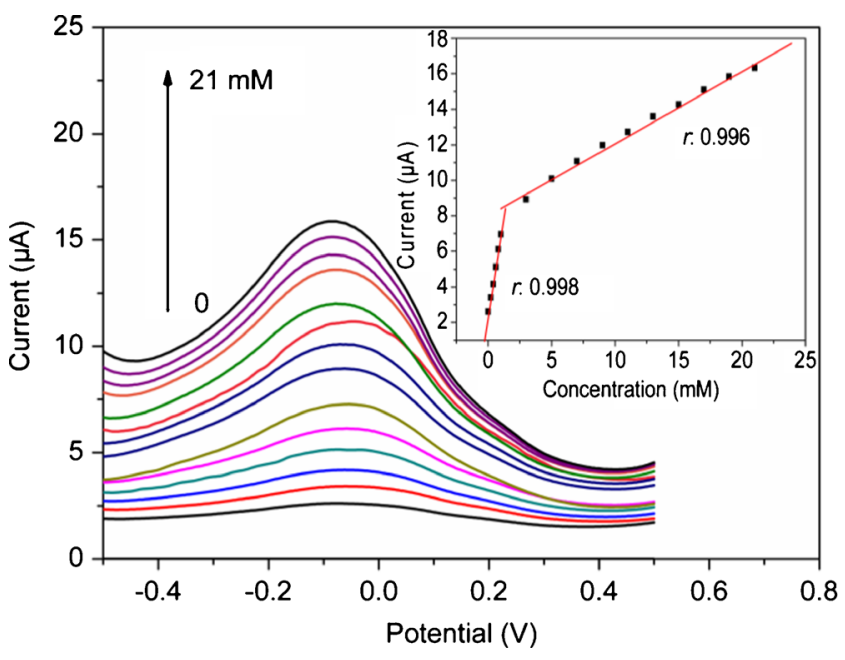

Fig. 6 DPVs of GOD/AuNPs/rGO/GCE in $\mathrm{O}_{2}$-saturated $0.2 \mathrm{M}$ PBS at $\mathrm{pH} 7.4$ with various concentrations of glucose (from down to top 0 , $0.2,0.4,0.6,0.8,1,3,5,7,9,11,13,15,17,19,21 \mathrm{mM})$. Inset: the calibration curves corresponding to the responses at $-0.07 \mathrm{~V}$

3. Note that our present sensing system gives lower detection limit than that of GOD/AuNPs/rGO/chitosan-based system $(180 \mu \mathrm{M})$ [39], GOD/AuNPs/rGO/ionic liquid (IL) biosensor $(130 \mu \mathrm{M})[40]$ and GOD-chemically modified graphene-IL $(376 \mu \mathrm{M})$ [41], etc. The relative standard deviation of the response to $1 \mathrm{mM}$ of glucose is $1.9 \%$ for ten successive measurements, indicating the good reproducibility of $\mathrm{GOD} / \mathrm{AuNPs} / \mathrm{rGO} / \mathrm{GCE}$. To evaluate the long-term stability of the glucose biosensor, the GOD/AuNPs/rGO/GCE was stored at $4{ }^{\circ} \mathrm{C}$ when not in use. The response to glucose at the GOD/AuNPs/rGO/GCE decreased to about $95 \%$ of its initial response current on the third day and about $91 \%$ after 10 days. The loss of the response current may be ascribed to the decrease of the enzyme activity during these days.

\section{Electrocatalytic effect toward hydrazine of AuNPs/rGO/GCE}

It is found that the resultant $\mathrm{AuNPs} / \mathrm{rGO}$ composites exhibit good catalytic performance toward hydrazine oxidation. Figure $7 \mathrm{a}$ shows the electrocatalytic responses of bare GCE and AuNPs/rGO/GCE toward the oxidation of hydrazine in $0.2 \mathrm{M}$ PBS at $\mathrm{pH} 7.4$ in the presence of $10 \mathrm{mM}$ hydrazine. The response of the bare GCE toward the oxidation of hydrazine is quite weak. In contrast, the AuNPs/rGO/GCE shows a notable current peak about $75 \mu \mathrm{A}$ in intensity centered at $0.3 \mathrm{~V}$ vs. $\mathrm{Ag} / \mathrm{AgCl}$; however, it exhibits no electrochemical response in the absence of hydrazine. These observations indicate that the observed current peak originates from hydrazine oxidation and the nanocomposites can effectively catalyze the electrochemical oxidation of hydrazine. The amperometric response of the hydrazine sensor was studied by successively dropping the hydrazine aqueous solution into the PBS at an applied potential of $0.3 \mathrm{~V}$ vs. $\mathrm{Ag} / \mathrm{AgCl}$ electrode (Fig. 7b). When an aliquot hydrazine was dropped into the stirred PBS solution, the oxidation current rose steeply to reach a stable value. The sensor could accomplish $96 \%$ of the steady state current within $3 \mathrm{~s}$, indicating a fast amperometric response behavior. The inset in Fig. $7 \mathrm{~b}$ shows the calibration curve of the sensor. The linear detection range is estimated to be from 5 to $900 \mu \mathrm{M}(r=0.999)$, and the detection limit is estimated to be $0.08 \mu \mathrm{M}$ at a signal-to-noise ratio of 3 . Note that our present sensing system gives lower detection limit than that of platinum screen-printed electrodes $(0.12 \mu \mathrm{M})$ [42], AuNPs on thiolated single-stranded DNA-modified $\mathrm{Au}$ electrode

A

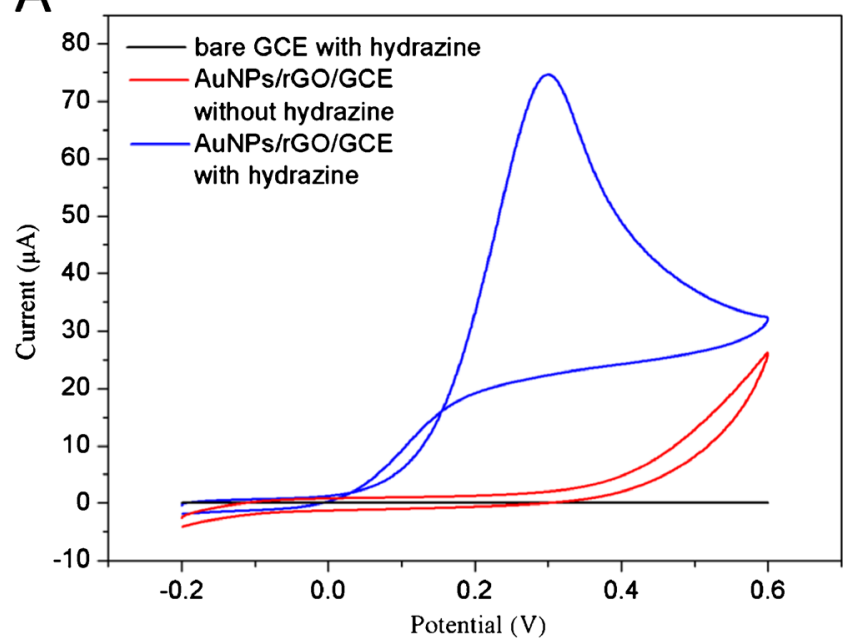

B

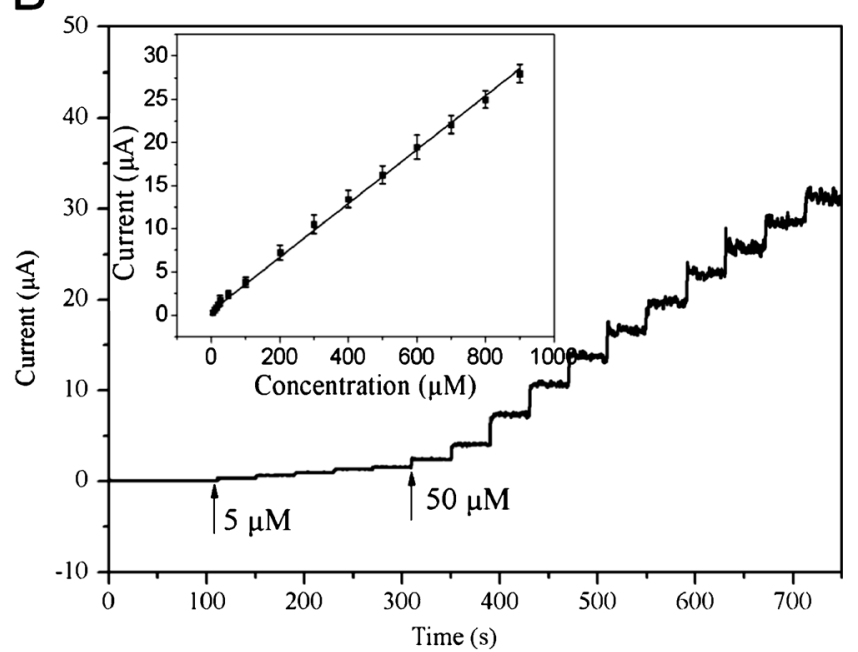

Fig. 7 a CVs of different electrodes in $0.2 \mathrm{M}$ PBS at pH 7.4 in the presence and absence of $10 \mathrm{mM}$ hydrazine (scan rate, $50 \mathrm{mV} \mathrm{s}^{-1}$ ). b Typical steady-state response of the AuNPs/rGO/GCE to successive injection of hydrazine into the stirred $0.2 \mathrm{M}$ PBS at pH 7.4 (applied potential, $0.3 \mathrm{~V}$ ). Inset: the fitting of the experimental data by the regression line 
$(0.56 \mu \mathrm{M})$ [43], and hybrid nickel hexacyanoferratefunctionalized multiwalled carbon nanotube/GCE [44].

\section{Conclusions}

In summary, heating treatment of $\mathrm{HAuCl}_{4}$ and preformed GO solution under alkaline condition has been proven to be an effective strategy to one-pot preparation of AuNPs/rGO nanocomposites without an extra reducing agent. Such nanocomposites exhibit good electrocatalytic activity toward $\mathrm{H}_{2} \mathrm{O}_{2}$ reduction and oxidation as well as hydrazine oxidation. Electrochemical detection of $\mathrm{H}_{2} \mathrm{O}_{2}$, glucose, and hydrazine is also demonstrated successfully. Our present study is important because it provides us a simple method for preparing noble metal nanoparticles/rGO composites for sensing and other applications.

Open Access This article is distributed under the terms of the Creative Commons Attribution License which permits any use, distribution, and reproduction in any medium, provided the original author(s) and the source are credited.

\section{References}

1. Novoselov KS, Geim AK, Morozov SV, Jiang D, Zhang Y, Dubonos SV, Grigorieva IV, Firsov AA (2004) Science 306:666-669

2. Kim K, Park HJ, Woo BC, Kim KJ, Kim GT, Yun WS (2008) Nano Lett 8:3092-3096

3. Lee C, Wei X, Kysar JW, Hone J (2008) Science 321:385-388

4. Huang X, Li S, Huang Y, Wu S, Zhou X, Li S, Gan CL, Boey F, Mirkin CA, Zhang H (2011) Nat Commun 2:292

5. Huang X, Li H, Li S, Wu S, Boey F, Ma J, Zhang H (2011) Angew Chem Int Ed 50:12245-12248

6. Yan L, Zheng Y, Zhao F, Li S, Gao X, Xu B, Weiss PS, Zhao Y (2012) Chem Soc Rev 41:97-114

7. Huang X, Zhou X, Wu S, Wei Y, Qi X, Zhang J, Boey F, Zhang H (2010) Small 6:513-516

8. Huang X, Li S, Wu S, Huang Y, Boey F, Gan CL, Zhang H (2012) Adv Mater 24:979-983

9. Wu S, He Q, Zhou C, Qi X, Huang X, Yin Z, Yang Y, Zhang H (2012) Nanoscale 4:2478-2483

10. Guo S, Dong S (2011) Chem Soc Rev 40:2644-2672

11. Huang X, Qi X, Boey F, Zhang H (2012) Chem Soc Rev 41:666-686

12. Tan C, Huang X, Zhang H (2013) Mater Today 16(16):29-36

13. Liu S, Tian J, Wang L, Sun X (2011) Carbon 49:3158-3164

14. Liu S, Tian J, Wang L, Sun X (2011) J Nanopart Res 13:4539-4548

15. Zhang Y, Chang G, Liu S, Tian J, Wang L, Lu W, Qin X, Sun X (2011) Catal Sci \& Technol 1:1636-1640
16. Zhang Y, Liu S, Lu W, Wang L, Tian J, Sun X (2011) Catal Sci \& Technol 1:1142-1144

17. Zhang Y, Liu S, Wang L, Qin X, Tian J, Lu W, Chang G, Sun X (2012) RSC Adv 2:538-545

18. Lu W, Ning R, Qin X, Zhang Y, Chang G, Liu S, Luo Y, Sun X (2011) J Hazard Mater 197:320-326

19. Liu S, Wang L, Tian J, Lu W, Zhang Y, Wang L, Sun X (2011) J Nanopart Res 13:4731-4737

20. Wu T, Liu S, Luo Y, Lu W, Wang L, Sun X (2011) Nanoscale 3:2140-2142

21. Li H, Liu S, Tian J, Wang L, Lu W, Luo Y, Asiri AM, Al-Youbi AO, Sun X (2012) Chem Cat Chem 4:1079-1083

22. Li H, Chang G, Zhang Y, Tian J, Liu S, Luo Y, Asiri AM, Al-Youbi AO, Sun X (2012) Catal Sci \& Technol 2:1153-1156

23. Li H, Zhang Y, Chang G, Liu S, Tian J, Luo Y, Asiri AM, Al-Youbi AO, Sun X (2012) Chem Plus Chem 77:545-550

24. Zhou X, Huang X, Qi X, Wu S, Xue C, Boey F, Yan Q, Chen P, Zhang H, Phys J (2009) Chem C 113:10842-10846

25. Tian J, Liu S, Zhang Y, Li H, Wang L, Luo Y, Asiri AM, Al-Youbi AO, Sun X (2012) Inorg Chem 51:4742-4746

26. Qin X, Luo Y, Lu W, Chang G, Asiri AM, Al-Youbi AO, Sun X (2012) Electrochim Acta 79:46-51

27. Kannan PR, Swami A, Srisathiyanarayanan D, Shirude PS, Pasricha R, Mandale AB, Sastry M (2004) Langmuir 20:78257836

28. Fan X, Peng W, Li Y, Li X, Wang S, Zhang G, Zhang F (2008) Adv Mater 20:4490-4493

29. Wang X, Wu H, Kuang Q, Huang R, Xie Z, Zheng L (2010) Langmuir 26:2774-2778

30. Nishimure S, Mott D, Takagaki A, Maenosono S, Ebitani K (2011) Phys Chem Chem Phys 13:9335-9343

31. Hummers WS Jr, Offeman R (1958) J Am Chem Soc 80:1339-1339

32. Li Z, Yao Y, Lin Z, Moon KS, Lin W, Wong C (2010) J Mater Chem 20:4781-4783

33. Zhang Y, Guo L, Wei S, He Y, Xia H, Chen Q, Sun H, Xiao F (2010) Nano Today 5:15-20

34. Guo Y, Guo S, Ren J, Zhai Y, Dong S, Wang E (2010) ACS Nano 4:4001-4010

35. Sediri F, Gharbi N (2007) Mater Sci Eng B 139:114-1177

36. Daniel MC, Astruc A (2004) Chem Rev 104:293-346

37. Chandra V, Park J, Chun Y, Lee JW, Hwang I, Kim KS (2010) ACS Nano 4:3979-3986

38. Tsai M, Tsai Y (2009) Sens Actuators B 141:592-598

39. Shan C, Yang H, Han D, Zhang Q, Ivaska A, Niu L (2010) Biosens Bioelectron 25:1070-1074

40. Yang M, Choi BG, Park TJ, Hong WH, Lee SY (2011) Electroanal 23:850-857

41. Yang MH, Choi BG, Park H, Hong WH, Lee SY, Park TJ (2010) Electroanal 22:1223-1228

42. Metters JP, Tan F, Kadara RO, Banks CE (2012) Anal Methods 4:1272-1277

43. Chang G, Luo Y, Lu W, Hu J, Liao F, Sun X (2011) Thin Solid Films 519:6130-6134

44. Kumar AS, Barathi P, Pillai KC (2011) J Electroanal Chem 654:85-95 